\title{
Envolvimento ambiental, caminho sustentável e a defesa da sociobiodiversidade na Reserva Extrativista do Extremo Norte do Tocantins
}

\author{
Environmental involvement, sustainable way and the defense of sociobiodiversity in the Reserve \\ of the Extreme North of Tocantins
}

\author{
Fábio Pessoa Vieira ${ }^{1}$ \\ Lucas Barbosa Souza ${ }^{2}$
}

\begin{abstract}
Resumo
$\mathrm{O}$ artigo visa apresentar outra possibilidade de sustentabilidade. Possibilidade distante de uma ideia de desenvolvimento sustentável disciplinada por uma racionalidade econômica. Para tanto apresentaremos o caminho sustentável, constituído a partir do envolvimento ambiental das quebradeiras de coco, da Reserva Extrativista do Extremo Norte do Tocantins, com o seu território. O pós-colonialismo e a fenomenologia alicerçam teoricamente e epistemicamente as tramas para o caminho sustentável. A fenomenologia é também, o método para a consecução da pesquisa, com foco em suas compreensões humanistas, além da técnica da pesquisa-ação existencial. Como resultados, compreendemos a sustentabilidade reconfigurando-se e sendo produzida em um diálogo com outros saberes, rompendo com o pensamento produzido pela sociedade moderno-colonial que impõe uma única maneira de ser sustentável, desprezando as experiências vividas e o os diversos saberes. Por fim, acreditamos que relação, a partir do envolvimento ambiental, que as quebradeiras de coco da Reserva Extrativista do Extremo Norte do Tocantins possuem com o seu território propiciam uma real conservação da sociobiodiversidade.
\end{abstract}

Palavras-Chave: Sociobiodiversidade; Caminho sustentável; Território; Reserva extrativista

\begin{abstract}
The article aims to present another possibility of sustainability, that is, far from an idea of sustainable development disciplined by an economic rationality. For that, we will present the sustainable way, constituted from the environmental involvement of coconut breakers, from the Extractive Reserve of the Far North of Tocantins, with its territory. Postcolonialism and phenomenology, theoretically and epistemically ground the plots for the sustainable way. Phenomenology is also the method for the pursuit of research, with a focus on its humanistic understandings, as well as the existential research-action technique. As a result, we understand sustainability by reconfiguring itself and being produced in a dialogue with other knowledge, breaking with the thinking produced by modern-colonial society that imposes a unique way of being sustainable, disregarding the lived experiences and the various knowledges. Finally, we believe that the relation, from the environmental involvement, that the coconut breakers of the Extractive

\footnotetext{
${ }^{1}$ Doutorando em Ciências do Ambiente. Professor Assitente da (UFT) Universidade Federal do Tocantins. Campus de Tocantinópolis-TO. E-mail: fabiopessoa@uft.edu.br

${ }^{2}$ Doutor em Geografia. Professor Associado da (UFT) Universidade Federal do Tocantins. Campus de Porto NacionalTO. E-mail: ibsgeo@mail.uft.edu.br
} 
Reserve of the Far North of Tocantins possess with their territory, provide a real conservation of the sociobiodiversity.

Keywords: Socio-biodiversity; Sustainable way; Territory; Extractive reserve

\section{Introdução}

O presente texto emerge em busca de compreender um caminho legitimamente sustentável, que se delineie com o intuito de contrapor a ideia de que o desenvolvimento sustentável é único para todos os locais. O uso do termo legitimamente 3 para se alcançar o caminho sustentável, surge como algo autêntico. Uma autenticidade alicerçada nos mais diversos lugares, tendo como referência a relação do ser humano com seus pares e com a natureza, e a sua territorialidade, destoando da abordagem imposta vigente de um modelo uno de desenvolvimento sustentável.

A busca ao caminho sustentável emerge, também, epistemicamente, como um contraponto ao discurso do desenvolvimento e do progresso, associado à ideia de desenvolvimento sustentável, como se este fosse homogêneo nos diversos espaços tempos, desprezando as singularidades dos territórios e dos lugares. Tal homogeneização apresenta-se como uma imposição em uma relação colonial vigente no nosso mundo.

Essa concepção de imposição refere-se à forma com a qual a humanidade, apoiada pelo paradigma da modernidade, relaciona-se com a natureza - tornada como mercadoria, passível de apropriação desigual por parte de diferentes grupos sociais - de maneira exploratória e pautada por uma racionalidade econômica. Tal forma de relacionar-se ganha ênfase com a conformação do mundo moderno-colonial e se mantém até os dias atuais, potencializada pelo discurso do desenvolvimento sustentável. Discurso este que visa uma conservação dos recursos naturais com o intuito de manter um status quo da natureza como mercadoria.

Logo, o objetivo proposto neste artigo é o de apresentar o que denominamos de caminho sustentável, em contraponto à ideia corrente de sustentabilidade, imposta pelo mundo modernocolonial. Tal relação será destacada a partir do envolvimento das quebradeiras de coco, da Reserva Extrativista do Extremo Norte do Tocantins - localizada nos municípios de Sampaio, Buriti do Tocantins e Carrasco Bonito - com o seu território, permitindo uma real conservação da sociobiodiversidade, em um movimento autônomo que visa à subsistência de sua comunidade.

\footnotetext{
${ }^{3}$ No decorrer do texto, o termo não será mais utilizado, porém a sua concepção estará implícita na perspectiva de que tal caminho é construído a partir das experiências vividas com o lugar e a partir de um movimento autônomo dos sujeitos em seu território.
} 
Como aporte teórico e epistêmico para o presente estudo, utilizamos o pós-colonialismo e a fenomenologia. Com o primeiro intentamos uma desconstrução paradigmática, que visa propiciar destaque ao lugar, no qual o caminho sustentável seja visível e perceptível como outra possibilidade de interação entre o ser humano e a natureza. Aliada ao pós-colonialismo, a fenomenologia reforça uma escolha paradigmática para a produção de conhecimento que valide o caminho sustentável, no qual os sujeitos e seus saberes dialoguem. Como corrente epistemológica, a fenomenologia "[...] estuda a aparição do ser para a consciência, em lugar de supor a sua possibilidade previamente dada" (MERLEAU-PONTY, 1999, p. 96). Trata-se, pois, de um caminho que possa vir a ser descrito no cotidiano, através das experiências vividas pelos sujeitos.

Sendo assim, usamos a fenomenologia como método para a pesquisa, com foco em suas compreensões humanistas, além da técnica da pesquisa-ação existencial, no intuito de apresentar a possibilidade de realização de um caminho sustentável por meio da experiência vivida dos extrativistas. Logo, por se tratar de uma investigação de cunho qualitativo, quando coletamos as descrições verbais das quebradeiras de coco não visamos utilizar as descrições como uma mera técnica de pesquisa, mas sim como uma expressão das experiências vivida por elas.

A estrutura do artigo centra-se em quatro momentos: o surgimento do mundo modernocolonial e como, neste mundo, emerge o discurso do desenvolvimento sustentável; a proposição do envolvimento ambiental como pilar para se alcançar o caminho sustentável; os passos para compreender o caminho sustentável na reserva extrativista; e, por fim, o vivido na reserva extrativista, a partir das descrições dos sujeitos, para apresentar como se realiza o caminho sustentável nesse contexto.

\section{A criação de um mundo e o discurso de um desenvolvimento sustentável}

Um padrão de poder que passa a governar o mundo e que tem como evento central a invasão do continente americano pelos europeus, a partir do final do século XV, dá início a uma primazia europeia de organização de mundo. Um mundo que passa a não ser mais, em termos espaciais e territoriais, a própria Europa. Assim, Quijano e Wallesrtein (1992, apud MIGNOLO, 2005) denominaram tal modelo de mundo moderno-colonial.

As bases para a consolidação de tal modelo teve como pilares a colonização do continente americano, com a escravização de diversos povos, sobretudo os indígenas, bem como negros sequestrados da África. Isto ocasionou a destruição, em larga escala, das florestas destes 
continentes, seja para a retirada de metais preciosos como ouro e prata, seja para a implantação das monoculturas, o que deu início ao processo de espoliação da natureza em larga escala.

Ao divergirmos da perspectiva colonizadora do mundo moderno-colonial sobre o território, as territorialidades e as possibilidades de territorialização, compreendemos que o território é um espaço múltiplo, produzido a partir da complexidade e da riqueza existente no lugar, denotando os aspectos simbólicos na produção do espaço. Associado ao simbólico há o entendimento de que a dimensão funcional sobre o território é real e dar-se-á conforme destaca Haesbaert (2005, p. 6776): “[...] todo território é, ao mesmo tempo e obrigatoriamente, em diferentes combinações, funcional e simbólico, pois exercemos domínio sobre o espaço tanto para realizar "funções" quanto para produzir "significados" [...]".

Logo, compreendemos que há possibilidades de uma territorialização a partir de territorialidades existentes com o lugar, construídas de maneira autônoma, e que ressoe em uma defesa dos povos tradicionais e de toda uma rede de saberes existentes com eles. Entretanto, historicamente, a exploração e expropriação dos povos do Sul pelos do Norte, pelo fato de unifuncionalizar o território pelo viés economicista, negou os percursos no espaço tempo que poderiam assegurar uma diversidade de territorializações aos próprios povos tradicionais e detentores de saberes elaborados com o lugar. Tal negação reflete-se na inviabilidade de defesa da sociobiodiversidade existente com e por esses povos.

Assim, o mundo moderno-colonial, pautado por uma lógica produtivista dos lugares e dos territórios e orientado por um viés desenvolvimentista para com a natureza, passa a constituir a ideia de tornar privados os elementos existentes nesta natureza. Priva-se, então, o direito dos próprios povos de se relacionarem com o seu lugar, indo de encontro a uma concepção da natureza como algo público e um bem comum à humanidade, o que desencadeou ao longo do tempo e do espaço profundas mudanças na Terra.

Leff (2006), ao tecer uma teorização sobre a crise ambiental, permite pensar a possibilidade de construir outros caminhos, visando romper com o paradigma da modernidade.

[...] a crise ambiental problematiza os paradigmas estabelecidos do conhecimento e demanda novas metodologias capazes de orientar um processo de reconstrução do saber que permita realizar uma análise integrada da realidade (LEFF, 2006, p.60).

Destarte, a perspectiva aqui trabalhada, ao defender outro caminho de produção de conhecimento, tendo como base um diálogo entre saberes, emerge da necessidade de compreendermos que, pelo fato de a maior parte do mundo não estar incluída no ideal de progresso 
do mundo colonial, é que existe a possibilidade de discutirmos a epistemologia pós-colonial, definida por Santos (2010) como:

[...] um conjunto de correntes teóricas e analíticas, com forte implantação nos estudos culturais, mas hoje presentes em todas as ciências sociais, que têm em comum darem primazia teórica e política às relações desiguais entre o Norte e o Sul na explicação ou na compreensão do mundo contemporâneo (SANTOS, 2010, p. 28).

Por conseguinte, o diálogo entre saberes cria condições para pensarmos outras formas de relação com a natureza e com o território, diferentes daquelas impostas pelo mundo modernocolonial. Trata-se de permitir que saberes outros, historicamente considerados menos válidos que o conhecimento científico, a partir da lógica da monocultura científica, possam emergir nos espaços de discussão e produção do conhecimento.

Entretanto, o que foi constituído pelo paradigma da modernidade como maneira única de se relacionar com a Terra, por intermédio da subjugação de saberes e de uma rede de multiplicidades espaciais existentes, foi um modelo de desenvolvimento que fissurou ontologicamente a relação do ser humano com o seu lugar. Uma relação que passou a criar fendas, não só no contato dos humanos com o seu lugar, bem como na natureza, por intermédio de uma perspectiva colonizadora, imposta em especial na América do Sul e na África, após a segunda Guerra Mundial, quando:

[...] os EUA tomaram a liderança que era da Inglaterra e da França, e substituíram a missão de civilização dessas pela sua própria versão de modernização e desenvolvimento. Ficou aparente, lá pelo fim dos anos sessenta e início dos setenta - com a crise do Estado do Bem-estar (Welfare State) - que "desenvolvimento" era um outro termo na retórica da modernidade para esconder a reorganização da lógica da colonialidade: as novas formas de controle e exploração do setor do mundo rotulado como Terceiro Mundo e países subdesenvolvidos. (MIGNOLO, 2008, p.293).

Não obstante, havia um "impasse" de ordem natural para ampliar a modernização tecnológica nos países centrais e expandir, por meio do discurso, para os demais espaços mundiais. Esse impasse foi imposto pela própria maneira excludente e progressista de desenvolvimento, constituída no paradigma da modernidade, que transforma a natureza meramente em recursos mercantilizáveis e estes, por sua vez, que são explorados como se fossem inesgotáveis.

Ao atualizarmos as ações de tal paradigma, aferimos que há a apropriação de um discurso de conservação e de exploração racional da natureza, tal como prega o desenvolvimento sustentável. Todavia, existe forte intencionalidade na criação de um negócio altamente lucrativo, em especial 
apoiado em novas tecnologias e em mercados específicos de capital, que travestem a manutenção da lógica mercantil e da acumulação em solução para a problemática ambiental.

Países centrais e parte da comunidade científica passam a discutir e propor garantias para manutenção do desenvolvimento e do progresso, diante da grave crise ambiental que passou a ser apontada a partir da segunda guerra mundial, conforme destaca Rodrigues (2006):

A preocupação com o 'meio-ambiente' aparece, internacionalmente, de forma mais explicita na Conferência Científica da ONU - Sobre Conservação e Utilização de Recursos Naturais (UNSCCUR, 1949 em Nova York) com a proposta de adequar os recursos naturais que possam atender as exigências crescentes da produção e descobrir novos recursos com pesquisas científicas. A idéia central é o domínio da natureza por meio do avanço técnico/cientifico, considerado 'neutro'. (RODRIGUES, 2006, s.p).

Mais adiante, diferentes eventos se propuseram a discutir os problemas ambientais existentes na Terra. Dentre eles, a primeira Conferência da ONU, em 1972, sobre o meio ambiente, na qual houve debates que se sucederam e estabeleceram uma relação binária no que se refere ao desenvolvimento. Rodrigues (2006) aponta que, nestes debates, países do Norte apresentaram uma proposta de crescimento zero e os do Sul defendiam a possibilidade de desenvolvimento, mesmo que como consequência houvesse perda das riquezas naturais.

Assim, o que se vê é um forte componente da relação colonizador-colonizado presente no mundo. De um lado, os países do Norte, que em sua maioria entendiam que havia grandes riscos oriundos de avanços econômicos dos países do Sul, o que poderia por em risco os usos dos recursos naturais, existentes em abundância nos países periféricos, para continuar provendo elevados níveis de progresso e bem-estar social em seus próprios territórios. Do outro, os países do Sul, que queriam a qualquer custo alcançar níveis iguais ou próximos de progresso dos países que os colonizaram como se houvesse uma única forma de desenvolvimento.

Logo, o discurso progressista como sendo um direito de todos contribuía para fomentar um modelo de desenvolvimento que não só degrada a natureza em larga escala, como também empobrece as possibilidades de enraizamento do ser humano na Terra. Seja dos países centrais que buscavam alternativas para continuarem se desenvolvendo, seja dos países periféricos que construíam uma crítica contra a desigualdade do desenvolvimento e não ao modelo de desenvolvimento, um desenvolvimento sem autonomia, sem envolvimento...

Com o objetivo de manter o status quo desenvolvimentista, surge o conceito de desenvolvimento sustentável. Proposto pela ONU e presente em um documento nominado Nosso Futuro Comum (1991), tal conceito preconiza que é: “[...] aquele que atende às necessidades do 
presente sem comprometer as possibilidades das gerações futuras atenderem suas próprias necessidades" (COMISSÃO MUNDIAL DO MEIO AMBIENTE E DESENVOLVIMENTO, 1991.p. 9).

Ao ser construído pelos setores que controlam a política e a economia na sociedade moderna cientificista, legitimando o modelo desenvolvimentista vigente, o desenvolvimento sustentável, como algo imposto, dificulta a possibilidade de autonomia e as relações de pertencimento, construídas em diversas comunidades com o lugar. Assim, o desenvolvimento sustentável, pensado como mais um elemento de colonização não apenas dos lugares, mas, sobretudo, na produção de conhecimento, dificulta a compreensão das causas estruturais da crise ambiental. Por sua vez, o que apontamos como estrutura da crise ambiental está no cerne da relação entre ser humano e natureza, na qual o primeiro passa a se desvincular da segunda, em um exercício que visa à dominação do primeiro sobre a segunda.

Portanto, a ideia de desenvolvimento sustentável - originada como mais um elemento das formas de produção de conhecimento dominante da ciência moderna - é o conceito ao qual buscaremos contrapor, com o propósito de valorizar uma perspectiva de integração entre o ser humano e a natureza.

\section{Um envolvimento ambiental e um caminho sustentável}

Com o intuito de objetar a ideia de desenvolvimento sustentável, ora apresentada, lançamos a perspectiva do envolvimento ambiental. Tal perspectiva - por mais que as palavras possam indicar uma redundância à medida que o ambiente nos envolve, nos circunda - refere-se a outro viés relacional com o ambiente. Busca-se percebê-lo e valorá-lo em uma perspectiva de construir uma relação com a natureza pautada por uma ética ambiental, orientada por um relacionamento no qual o cotidiano, o vivido, sejam fundantes. É um relacionar-se de modo diverso, a partir de outros preceitos e propósitos.

Com isso, visamos a um envolvimento em que o comprometimento contra a atual degradação ambiental crie condições para que um novo paradigma se assente. Um paradigma que propicie um engajamento pensado no lugar e pelo seu próprio povo, de maneira autônoma e não por agentes externos, no sentido de compreender um caminho sustentável. 
Ao buscarmos o significado da palavra envolver em um dicionário da língua portuguesa (MICHAELIS, 2015), encontramos a seguinte definição: “entremeter-se, incluir-se, comprometerse".

Em outro trabalho, destacamos que a perspectiva de desenvolvimento sobre a natureza tem como base a não inclusão, o não comprometimento com o ambiente, uma vez que o prefixo des possui o sentido de: "separação, ação contrária". Assim, tal perspectiva cria condições para a degradação ambiental, a partir de um desenvolvimento que nega as subjetividades e o pertencimento com o lugar e com a própria natureza (VIEIRA, 2014).

$\mathrm{Na}$ tentativa de termos uma alternativa ao modelo de desenvolvimento do mundo modernocolonial, buscamos mais uma vez, com o auxílio de um dicionário da língua portuguesa (MICHAELIS, 2015), o significado de uma palavra - dessa vez envolvimento. Algumas das definições particularmente nos interessam: "inclusão; comprometimento; engajamento; ligação". Desse modo, compreendemos que com a perspectiva do envolvimento ambiental há uma relação de intimidade e afetividade com o lugar, que cria condições para que um novo paradigma científico se assente.

Por conseguinte, tomando como base as quebradeiras de coco da Reserva Extrativista do Extremo Norte do Tocantins, a perspectiva do envolvimento ambiental se efetua a partir de um exercício ético, que se realiza no dia a dia, e que é produzido por possibilidades de práticas cotidianas que visam alcançar: a) a subsistência, pensada como um sustento em busca de uma dignidade que não exclui a possibilidade de mudanças no âmbito material; b) a conservação ambiental, que se efetiva a partir de uma resistência em defesa do babaçual; c) e a justiça social, que se assenta em uma luta pelo direito de uso dos extrativistas pelo território da RESEX.

A construção desse envolvimento, no mundo das possibilidades, ocorre por uma diversidade de culturas, saberes e identidades, que dão outro significado para o que é ser sustentável, distante de um significado único e universal, coadunando com o pensar de Leff (2010):

[...] a sustentabilidade baseada em uma política da diversidade e da diferença implica fazer descer de seu pedestal o regime universal e dominante do mercado como medida de todas as coisas, como princípio organizador do mundo globalizado e do próprio sentido da existência humana (LEFF, 2010, p.26).

E, para romper com o universal do mundo globalizado, o lugar emerge como um conceito que possui ressonâncias na abordagem topofílica de Tuan (2012), a partir de um sentimento de pertencimento e de envolvimento. Para Tuan (2002, p. 19), o conceito de topofilia trata de um "[...] 
elo afetivo entre a pessoa e o lugar ou ambiente físico. Difuso como conceito vivido e concreto como experiência pessoal [...]”. Esta definição de topofilia não só se alinha com a perspectiva do envolvimento ambiental, assim como ratifica a percepção conforme a ideia de ter, para tal envolvimento, uma relação com o lugar a partir das experiências vividas.

O propósito de dar potência ao lugar não se refere a uma negação das demais escalas de realização do vivido, não exclui a interligação entre as mais diversas escalas, tais como a regional e a global. Com Relph (2012), reforçamos o viés humanista e aproximamos o lugar e o mundo, o local com o global, à medida que é por intermédio dos lugares que nos relacionamos com o mundo:

"Lugar é um microcosmo. É onde cada um de nós se relaciona com o mundo e onde o mundo se relaciona conosco. O que acontece aqui, neste lugar, é parte de um processo em que o mundo inteiro está de alguma forma implicado" (RELPH, 2012, p.31).

Não obstante, acreditar na relação do ser humano com a natureza, a partir de suas experiências, torna-se uma oposição radical a uma forma única e dominante de pensarmos o desenvolvimento sustentável. Para tanto, buscaremos radicalizar - no sentido de ousar -, teórica e filosoficamente, para propormos uma trajetória de pensarmos um caminho sustentável como produto das experiências humanas. Uma radicalização alicerçada em Merleau-Ponty (1999), na qual a busca pela descrição do caminho sustentável apresenta-se sem a pretensão de alcançar um caminho absoluto, mas sim de descrever um caminho sustentável que se baseie em um exercício filosófico que priorize uma trajetória do vivido como fundante.

\section{Os passos para o caminho sustentável na Reserva Extrativista do Extremo Norte do Tocantins: o vivido como fundante}

Acreditamos que a rica cultura e os saberes constituídos pelas quebradeiras de coco com o ambiente se refletem em uma defesa da sociobiodiversidade. Segundo essa perspectiva, as atividades primeiras de relação do ser humano com a natureza permitem maior envolvimento entre ambos, a partir de uma territorialização e de um lugaridade exercidas por populações tradicionais cuja subsistência baseia-se no extrativismo.

O lócus empírico para a observação da relação afetiva do ser humano com a natureza, no campo de real, do vivido, é a Reserva Extrativista do Extremo Norte do Tocantins, que tem no babaçu (attalea speciosa) o principal recurso para a subsistência das famílias beneficiárias. Apesar do extrativismo ser alicerçado no coco babaçu, que representa 82,07\% dos frutos extraídos na área 
da RESEX, há outros alimentos existentes, dos quais os extrativistas fazem uso para seu sustento. Conforme destacado em um estudo realizado pela Universidade Federal de Viçosa, em parceria com o ICMBio, feito em 2014, esses outros alimentos são: o açaí (7,59\%), o buriti (5,52\%), o murici $(1,38 \%)$ e demais frutas $(3,44 \%)$ (UFV/ICMBIO, 2014).

A reserva extrativista se situa na região denominada Bico do Papagaio, ao Norte da estrada TO-496 e ao Sul do rio Tocantins, na divisa com o Estado do Pará, a Oeste, e com o Estado do Maranhão, a Leste. Foi criada pelo decreto $\mathrm{n}^{\circ} 535$ de 20 de maio de 1992, sendo gerida pelo ICMBio - Instituto Chico Mendes de Conservação da Biodiversidade. A área da RESEX está inserida, predominantemente, no bioma Cerrado, no entanto a mesma encontra-se em uma zona de transição para a Floresta Amazônica. Silva (2007) destaca que nesta região o recobrimento da vegetação vai diminuindo gradativamente de densidade, advindo daí seu nome, Floresta Ombrófila Aberta. Esta formação florestal refere-se à transição entre o cerradão e a floresta ombrófila densa, e tem fisionomia mais clara e aberta, e sua composição fitoecológica está ligada a climas com mais de 60 dias secos por ano, apresentando uma diversidade de palmeiras.

A área da RESEX abrange três municípios: Sampaio, Buriti do Tocantins e Carrasco Bonito - neste último se localizam 90\% de sua área - todos no Estado do Tocantins, chegando ao quantitativo de 9.070,48 ha de extensão, com uma população de 893 pessoas beneficiárias, de acordo com um estudo técnico realizado pela UFV/ICMBio (2014).

Aqui vale salientar que todos os beneficiários estão no entorno da reserva, pelo fato de não haver regularização fundiária e, consequentemente, não ser "permitido" moradias nas áreas que hoje estão sob o domínio de fazendeiros, em propriedades privadas. Fazendeiros que desmatam o babaçual para cultivo de pasto e consequentente criação de gado. Por conseguinte, a área da RESEX configura-se, nesse caso, como um território em litígio.

No momento ainda não há o plano de manejo, da referida RESEX, devido a dificuldades operacionais encontradas pelo Conselho Gestor Deliberativo, que foi instituído pela Portaria $\mathrm{n}^{\circ} 24$ de 20 maio de 2011, em especial por não conseguir reunir seus membros, o que certamente é reflexo das condições de litígio expostas, uma vez que, de acordo com as próprias quebradeiras de coco, há um sentimento de desmotivação por conta da questão fundiária.

Assim, a falta de regularização torna-se um fator provocador de conflitos entre fazendeiros e extrativistas. Conflitos que opõem a propriedade privada, representada pelos fazendeiros, ao uso e a vivência na RESEX, a partir de um senso comunitário, de um envolvimento, por parte dos extrativistas. 
Tal envolvimento passa a dar maior visibilidade e força à luta dos comunitários, com a implantação da Associação da Reserva Extremo Norte do Tocantins - ARENT, no ano de 2001. Nessa associação estão organizados os extrativistas da referida RESEX, sendo que atualmente existem 228 famílias diretamente ligadas à associação. Os associados visam deter o controle da gestão do babaçu e acabam por realizar uma defesa da natureza, erigida pelos próprios associados por meio de seus saberes.

Ao se posicionarem por uma territorialidade que visa ao uso comunitário da terra e ao buscarem uma efetiva territorialização por intermédio de uma organização que emerge no seu vivido, compreendemos que os extrativistas criam trajetórias para pensarmos em um caminho sustentável alicerçado no e com o lugar, a partir de uma relação de pertencimento com o território. Esse pertencimento se realiza em um envolvimento ambiental, com uma forma singular e diversificada de se viver em um lugar, em respeito às territorialidades construídas de maneira autônoma e, portanto, distantes da forma autoritária e hegemônica construída pelo paradigma da sociedade moderna e cientificista.

Escolhemos, para esta pesquisa, trabalhar com as descrições das quebradeiras de coco sobre as suas vivências na RESEX. Para compreendermos as descrições das quebradeiras de coco não foi lançado mão de uma questão (pergunta) específica, mas sim solicitado que descrevessem suas experiências, suas histórias de vida com o lugar, a partir do seu envolvimento ambiental. Tais descrições foram gravadas em arquivos digitais de áudio.

As descrições foram orientadas para contemplarmos a subsistência, a justiça social e a conservação ambiental. A orientação, aqui destacada, não se refere a um pedido específico para descrever sobre esses pilares do envolvimento ambiental, mas sim para contar sobre as experiências vividas nos lugares que, ao olhar do pesquisador, melhor representam esses pilares. Coaduna-se, assim, com as epistemologias pós-colonial e fenomenológica, no sentido de valorizar o lugar e as vivências dos sujeitos.

Os sujeitos, que permitiram a partir de suas descrições constituírem a pesquisa, possuem um papel de liderança frente a duas comunidades instaladas no entorno da RESEX - Centro dos Ferreira, localizada no município de Buriti do Tocantins; e Vinte Mil, que fica no município de Carrasco Bonito. A designação da liderança, ora apresentada, foi um exercício elaborado nos campos da pesquisa e na vivência do próprio pesquisador na RESEX, não apenas a partir de observações, mas, sobretudo, pelo que foi exposto e destacado pelos próprios associados.

O descrito tem como intuito propiciar uma compreensão acerca de como um caminho sustentável acontece no lugar, com as experiências, com o seu vivido. A potência concedida para as 
experiências vividas refere-se a uma tentativa de "corrigir" o que consideramos uma inconsistência metodológica da ciência, ao negar e/ou subjugar o vivido, em nome de uma consciência científica, que:

[...] toma de empréstimo às estruturas da experiência vivida todos os seus modelos; simplesmente ela não os "tematiza", não explicita os horizontes de consciência perceptiva pelos quais está envolvida e dos quais procura exprimir objetivamente as relações concretas (MERLEAU-PONTY, 1999, p.92).

Assim, foi feito uso do método fenomenológico existencial, ao compreender que o mesmo permite ser honesto com o cotidiano e com as experiências dos sujeitos, com o seu vivido. O nosso intuito é o de descrever o que está posto e não o de ditar como as coisas devem ser - no caso específico deste texto, a descrição de um caminho sustentável. Com isso, buscamos não apontar como o eu deve se relacionar com as coisas no mundo, uma vez que tais coisas se revelam para nós, não em um exercício de juízo de valor, mas sim por meio da percepção, pensada como uma vivência orientada ao mundo exterior, que não depende somente do elemento intelectual, mas também do corpo, por meio das sensações. Percepção que "[...] é tanto a resposta dos sentidos aos estímulos externos como a atividade proposital, na qual certos fenômenos são claramente registrados [...]" (TUAN 2012, p. 18).

Merleau-Ponty (2004) destaca que a nossa percepção sensível faz justiça à experiência humana e diz que "nossas relações com o espaço não são as de um puro sujeito desencarnado com um objeto longínquo, mas de um habitante do espaço com seu meio familiar" (MERLEAUPONTY, 2004, p. 16). Assim, a relação com o lugar vivido é de um sujeito imbricado com esse lugar, propiciando um envolvimento com o ambiente. Logo, compreende-se que um caminho sustentável pode ser pensado e descrito a partir desse envolvimento, por meio de uma atitude natural que ocorre a partir de um exercício, no qual: “[...] lançando-me no mundo das coisas, me dá a certeza de apreender um "real" para além das aparências, o "verdadeiro" para além da ilusão" (MERLEAU-PONTY, 1999, p.69).

Dessa maneira, à medida que o extrativista oferece suas descrições criam-se condições para que os significados existentes no descrito permitam uma compreensão, por meio das percepções das mais diversas manifestações topofílicas de caminhos sustentáveis do outro, a partir da intersubjetividade. Como destaca Souza (2013, p.40), “[...] compartilhamos de uma mesma estrutura, a estrutura transcendental, o que faz como que todos os indivíduos possam perceber, sentir, pensar, lembrar e imaginar segundo um mecanismo semelhante [...]”. São manifestações que 
desvelam as essências, que mesmo sendo experienciadas individualmente, compartilham algo em comum, em um exercício de universalidade da consciência humana.

Compreendemos que a percepção é altamente responsável pela forma como vemos o mundo. Mundo que, na verdade, por sua multiplicidade, decompõe-se em mundos possíveis, tantas quantas forem as percepções, pois cada um intenciona o seu olhar, a partir de referenciais, de informações, de conhecimentos adquiridos no percurso da vida. Percepção, que ao longo do espaço tempo e das experiências vividas, permite uma variabilidade de conteúdos, cujas percepções novas possam substituir as percepções antigas (MERLEAU-PONTY, 1999).

Para alcançarmos a intersubjetividade, em um exercício perceptivo realizado em uma vivência na RESEX, a trajetória metodológica elaborada teve como suporte o método fenomenológico, conforme já mencionado. Este método visa à subjetividade como constituinte fundamental na produção do conhecimento. Por isso, descarta, por parte do pesquisador, o préconcebido e propõe a busca de um retorno à própria consciência, como indica Gallefi (2000). Um retorno ao acontecimento das coisas, associado à vivência do ser humano em um mundo já existente, mas que não se encontra acabado e que tem em suas experiências a possibilidade de constituir outra ideia do que venha a ser a sustentabilidade.

Inicialmente, com essa epoché fenomenológica, buscamos abster-nos de emitir um entendimento prévio, para não trazermos prejuízo ao caminho sustentável a partir das percepções, do vivido. Portanto, não há nenhuma hipótese que se sobreponha ao real, ao vivido, sobre como se realiza um caminho sustentável. Após as leituras e releituras das descrições, passamos a identificar as unidades de significação, as entendendo como "[...] recortes julgados signifícativos pelo pesquisador, dentre os vários pontos aos quais a descrição pode levá-lo" (GARNICA, 1997, p.116).

A partir de então, foi realizada a redução à essência ou redução eidética. Para Garnica (1997), o objetivo dessa redução é excluir o conhecimento prévio do fenômeno, para estar na experiência concreta da vivência, por meio das descrições sobre a relação com o lugar, com a natureza e com o seu sustento, sua dignidade, contida nas descrições. Uma redução que é: "a resolução de fazer o mundo aparecer tal como ele é antes de qualquer retorno sobre nós mesmos" (MERLEAU-PONTY, 1999, p. 13).

Nas leituras e releituras do descrito, foi preponderante estarmos abertos para a descoberta e não irmos à busca de alguns trechos do que se esperava ou do que se acreditava sobre como se realiza o caminho sustentável. Procurou-se, dessa forma, uma contraposição a um caminho baseado em um modelo pronto, único e já conceituado de desenvolvimento sustentável, pensado 
impositivamente, desconsiderando as subjetividades e a relação com o lugar edificada pelos sujeitos que o compõem.

\section{O vivido pelos extrativistas e seus significados}

Ao buscarmos desvelar as estruturas do vivido pelos extrativistas, em busca de compreendermos o caminho sustentável por meio das suas experiências, denotaremos o significado que a Reserva Extrativista tem para os que nela vivem. Em um exercício fenomenológico, lançamos mão das descrições de sujeitos que em seu cotidiano fazem a luta extrativista acontecer.

Por se tratar de uma pesquisa qualitativa, cujo método se constitui por intermédio das subjetividades dos sujeitos, não se pretende chegar a generalizações, a uma metanarrativa do que seja o sustentável. Buscar-se-á no desvelamento do fenômeno, compreender a essência do caminho sustentável. A fim de obtermos uma descrição espontânea, explicamos o objetivo da nossa pesquisa e pedimos para que os extrativistas oferecessem descrições a partir de sua relação com o lugar. Isto nos concedeu explorar os significados subjetivos das suas experiências vividas na área que hoje é a reserva extrativista.

Depois de realizadas as transcrições do descrito, passamos a identificar as unidades de significação existentes nas mesmas e que permitiram a pesquisa se materializar. As unidades de significação escolhidas foram: babaçual; saber e cultura e território. Estas unidades de significação são recortes temáticos derivados do empírico, do vivido na RESEX, que emergiram nas descrições, as quais podem ser compreendidas como desdobramentos dos pilares do envolvimento ambiental: conservação ambiental, subsistência e justiça social.

Pela riqueza do vivido e do real, as unidades de significação escolhidas não se referem especificamente a um ou outro pilar do envolvimento ambiental. Há transcrições referentes a uma unidade de significação, mas que abordam mais de um ou até mesmo os três pilares do envolvimento ambiental.

A partir daí foi realizada a redução fenomenológica em busca de compreender como que, com a perspectiva do envolvimento ambiental, é possível se pensar um caminho sustentável que se realize no cotidiano e que destoe do conceito universal de desenvolvimento sustentável. Por fim, 
para nominar os sujeitos da pesquisa, resolvemos usar como referência produtos originados do babaçu. São eles: Caieira ${ }^{4}$ e Farinha ${ }^{5}$.

\section{Caieira}

Caieira é uma quebradeira de coco, nascida e criada no Bico do Papagaio, encontra-se há 25 anos no que hoje é o território da Reserva Extrativista. A nossa primeira conversa ocorreu em setembro de 2014, - os encontros sempre ocorreram na comunidade do Centro dos Ferreira, município de Buriti do Tocantins-TO - quando da primeira visita que realizamos na reserva. Meses depois e após algumas visitas, fizemos o registro da descrição - no dia 24 de Outubro de 2015 -, cujos trechos serão apresentados.

Assim, começamos com a descrição da unidade de significação saber e cultura, presente na fala de Caieira.

Moro aqui há 25 anos, nem me lembro mais. Nascida e criada aqui. Foi no Sabonete que eu nasci (Povoado de algum município, que a própria Caieira, não soube dizer, da Região do Bico do Papagaio. Precisou ir buscar o documento e ver que era de Araguatins). Aprendi a quebrar coco com minha avó. A geração mais nova da família (a filha única), sabe quebrar coco, vai pro mato mais é? A gente nunca sabe o dia de amanhã. Se precisar e eu pedir, ajuda sim. Tem que aprender né? Mas quer se formar em enfermeira. Eu não fui criada pra quebrar coco, mesmo com minha mãe e minha avó quebrando o coco. Quando a necessidade apertou, eu tive que aprender. Comecei a quebrar coco, com seis anos. Basta ter força, pra quebrar que nós aprende. Só que eu não queria ser quebradeira de coco. Se eu tivesse estudado eu queria ser uma enfermeira. Mas, daquelas enfermeiras-chefe. Mas nós era pobre e não tinha condição de estudar. Nem tinha escola por esse lados aqui. Teve outra coisa que aprendi com minha avó. Minha avó era parteira uma parteira muito boa. Bastava ela passar a mão na barriga, ela dizia: "Já tá quase na hora de nascer o bebê". Eu aprendi com ela isso também. Posso dizer que eu sou parteira e quebradeira de coco, com muito orgulho. Hoje mesmo tá com quatro meses que eu ajudei a botar um bebê no mundo. Sempre tem isso aqui: Bebê pra botar no mundo (Caieira, descrição sobre saber e cultura, gravada em 24 de Outubro de 2015).

Neste trecho da descrição, após o processo de redução e buscando associar com a perspectiva do envolvimento ambiental, destacamos a subsistência. Uma subsistência que se realiza por intermédio de um saber e de uma cultura que só ocorrem a partir de um enraizamento com o lugar.

\footnotetext{
${ }^{4}$ Forno artesanal produzido pelos extrativistas, que consiste na abertura de buracos feitos no solo, no qual as cascas, do coco babaçu, são condicionadas em um barril metálico que se encaixa nesses buracos. Por fim, essas cascas são abafadas com folhas da palmeira do babaçu e com a própria terra.

${ }^{5}$ Pó obtido, em um processo de moagem, do mesocarpo de babaçu (substância colhida entre o epicarpo e o endocarpo do coco de babaçu) e bastante utilizado na produção de bolos e mingau.
} 
Os aspectos descritivos de como se iniciou e se alicerçou um saber que emerge do cotidiano, no qual uma cultura local seja a base, revela-se uma experiência fenomenológica. Uma experiência que ocorre a partir de tradições culturais, transmitidas por quatro gerações de uma mesma família. No caso do babaçu, a experiência em ser uma quebradeira de coco se constitui em uma cultura, que quase sempre se refere ao gênero feminino.

$\mathrm{Na}$ fala de Caieira, ser quebradeira de coco, não por vontade própria, mas também por uma tradição familiar, não a impede de idealizar outro tipo de profissão, no caso a de enfermeira. Uma idealização que não se materializa pelas condições de pobreza impostas à sua família.

Contudo, a quebradeira de coco enfatiza a importância de um saber constituído com o seu ambiente, o babaçual, em cuja subsistência da família reside e com ele resiste. Há também, no trecho destacado, o outro trabalho que a mesma desenvolve na comunidade, o de ser parteira. Todavia, este não envolve rendimentos financeiros, o que não a impede de possuir uma constituição de um saber em uma relação cultural, na medida em que é transmitido por um saber familiar.

Ainda com Caieira, seguimos para outro trecho que representa mais uma unidade de significação:

Não pode desmatar, não pode derrubar as palmeiras. Se a pessoa desmatar ou derrubar as palmeiras como é que nós quebradeira de coco, vamos viver? Porque aí acaba tudo. É dele que nós tira o coco. O coco representa muita coisa, pois dele nós tira o azeite, nós tira o óleo, nós faz o sabão, nós faz o carvão pra cozinhar. Representa muita coisa. Representa a renda da família da gente. Ah, tem também o uso da palha, pra cobrir a casa. Nos últimos tempos, o babaçu vai ficando mais longe, por causa do desmatamento [...] Aqui sempre foi proibido a caçada de bicho. Eu sou a favor da proibição de caça. Eu acho certo. Até pra alimento próprio, porque os bichinhos quer sobreviver igual a gente. Sou a favor do peixe (pra comer), mas os bichinhos dos matos não. Aqui dá muito tatu, paca, peba (uma espécie de tatu de cor amarelada). Minha mãe sempre foi muito resguardada pra negócio de comida. Quando eu já tava mocinha, não comia tatu, não comia paca. A minha avó também. Nós mulheres não comíamos, pois muitas vezes quando estamos menstruadas, essas comidas pesadas podia dar ferida no corpo da gente. Os homens que podiam comer. Nós não. [...] Todo mundo aqui tem uma rocinha, no Babaçual. Nós planta o que der. Nós mexe com tudo. Arroz, feijão, fava, tudo a gente mexe. Hoje tamos precisando de uma casa de farinhada. Por que botamos ela de molho (a farinha) e temos de levar no assentamento lá no Carrasco Bonito. Hoje nós pagamos 30 a 40 reais em uma carrada (a carga de farinha que é transportada em um carro de terceiros, até o assentamento) de farinha. Eu tenho 53 anos, eu quebro coco, eu junto coco. Minha criação foi sadia, mesmo com todo esse trabalho. Só que nos últimos anos, o coco tá fraco. Um quilo a um real é muito pouco. É triste passar o dia inteiro, pra conseguir 5 quilos, e conseguir só 5 reais. A vida aqui é dureza meu filho.... Mas eu amo isso aqui. Não penso em sair daqui não (Caieira, descrição sobre o babaçual, gravada em 24 de Outubro de 2015). 
Com base no envolvimento ambiental do trecho relatado, no qual Caieira descreve a sua relação com o Babaçual, enfatizamos a conservação ambiental. Uma conservação que no vivido, no real, se funde com a subsistência.

Ainda sobre a dimensão ambiental, há um comentário favorável a respeito da proibição da caça de animais típicos da região, como algumas espécies de tatu. Há uma defesa pela vida destes animais, pelo fato dos mesmos "quererem" viver igual a nós. Após uma pergunta minha, sobre se existia outra justificativa, Caieira explica que se trata de uma questão cultural, ou seja, não comer as caças citadas por ela tem ligação com uma crença familiar segundo a qual durante o período menstrual as mulheres não deveriam comer tais tipos de alimentos, pois isso poderia implicar em infecções e ou alergias.

Ao dizer que não se deve desmatar o babaçual, uma vez que o coco babaçu e todos os produtos originados dele representam uma parcela significativa de suas rendas, Caieira nos propicia o entendimento de que o que "vier" do coco babaçu configura-se como um sustento para as quebradeiras. Ademais, é na área do babaçual que os extrativistas podem cultivar a roça, bem como plantar a mandioca, que se apresenta como outra fonte de renda importante para muitos extrativistas da RESEX - esta afirmação envolve também a nossa percepção nos trabalhos de campo realizados na RESEX em Extremo Norte.

A relação de enraizamento e pertencimento de Caieira com o babaçual revela-se de maneira ímpar, quando a mesma comenta sobre as dificuldades cotidianas existentes na RESEX. Isso se mostra, por exemplo, ao falar da redução, com o passar do tempo, do valor obtido pela venda do coco, mas o que não inviabiliza um amor ao lugar, a ponto da mesma afirmar que não pensa em sair de sua comunidade.

Continuamos com Caieira, com um trecho de sua descrição que explana o que identificamos como uma unidade de significação de território:

Eles (os fazendeiros) proíbe a gente de quebrar o coco lá dentro (das terras da reserva). Eles deixam a gente coletar e quebrar fora, porque dentro as cascas podem machucar o gado. Tem alguns fazendeiros que acham bom, quando a gente coleta o coco. Eles não importam. [...] Já faz um tempo que a gente luta, pra essas terra ser nossa. A gente já tá quase cansado. Se não servir pra mim, serve pra meus netos, pra minhas filhas. A esperança nunca morre. (Caieira, descrição sobre o território, gravada em 24 de Outubro de 2015).

Apoiados no envolvimento ambiental, o desejo por uma justiça social é representado na perspectiva da regularização fundiária da RESEX. A luta - palavra que bem expõe o fazer cotidiano 
em Extremo Norte - é histórica e, nas palavras de Caieira, há de conceder o tão desejado acesso livre ao babaçual.

O desejo em fazer com que a posse da terra seja dos extrativistas opõe-se a uma lógica privada da propriedade da terra. Um privado que na RESEX é representado pela propriedade dos fazendeiros, que em sua maioria criam gado, e que para a realização de tal atividade econômica derrubam o babaçual para o cultivo do pasto e para evitar o sombreamento excessivo do capim. Nesse caso, acabam por impedir a presença das quebradeiras de coco em suas propriedades.

Desta maneira, a defesa pelo uso comunitário do território implica: em uma justiça social, na medida em que visa reparar - ao menos no âmbito territorial da RESEX - um processo histórico de injustiça no acesso à terra, e em uma conservação ambiental, pois os extrativistas, ao defenderem o uso do território para a coleta do babaçu, defendem, por consequência, a conservação do babaçual.

\section{Farinha}

Natural do estado de Alagoas, Farinha encontra-se na RESEX, em Extremo Norte, desde 2008. Atualmente essa mulher, descendente de indígenas e com uma enorme capacidade de liderança frente às quebradeiras de coco, é a presidenta da ARENT. Farinha reside na Comunidade de Vinte Mil, localizada na zona rural do Município de Carrasco Bonito. Os trechos das descrições feitas por essa quebradeira de coco foram realizados em dois locais e momentos distintos. Uma ocorrida em Fevereiro de 2015, teve o seu registro feito na usina que a época era a responsável pela produção do óleo de babaçu, localizada na Comunidade de Vinte Mil, e cuja gerência era feita por Farinha. A outra ocorreu em Maio de 2016, em uma área de babaçual, no município de Carrasco Bonito.

Iniciaremos com trechos da descrição de Farinha que indicam a unidade de significação território.

As terras aqui não tinha dono, era terra do governo, isso uns 30 anos atrás. Depois os fazendeiros entraram e foram botando todo mundo pra fora. Depois, na época do GETAT ${ }^{6}$ ela saiu dando documentação pra todo mundo. Isso foi uma problemática para a RESEX. Se o governo não tivesse entregue a documentação para os fazendeiros, a regularização seria bem mais fácil. Hoje existem donos porque o governo deu a documentação para os fazendeiros. A comunidade extrativista só poderia trabalhar no interior da reserva, quando houvesse a regularização fundiária. $E$ isso até hoje não aconteceu. O que acontece hoje, na prática: nós vamos buscar o coco dentro da reserva pra quebrar fora. Isso é

\footnotetext{
6 Grupo Executivo das Terras do Araguaia-Tocantins, criado em 1980, com a finalidade de coordenar, promover e executar as medidas necessárias a regularização fundiária no Sudeste do Pará, Norte de Goiás e Oeste do Maranhão. Disponível em: < http://www.planalto.gov.br/ccivil_03/decreto-lei/1965-1988/Del1767.htm >.
} 
quando os fazendeiros deixam, pois alguns deles não deixam nem mais as quebradeiras coletarem o coco [...] $O$ azeite as quebradeiras vendem diretamente pra quem consome, em média $R \$ 10,00$ o litro. Vendem nas feiras, o povo da igreja, das escolas, compram diretamente da mão de quem produz. Isso dos municípios vizinhos todos daqui (Augustinópolis, Sampaio, Buriti, Carrasco Bonito, Imperatriz). Já o óleo é direcionado mais para cosmético, nós vendemos para empresa Beraca que fica em Belém e ela vende pra Alemanha. Hoje nós estamos perdendo muito, perdemos valor na venda do óleo. Vendemos a $R \$ 6,00 \mathrm{o}$ litro. É muito barato! Para eles (a Beraca) sai um valor bem maior, uns $R \$ 21,00$ bem alto por que eles podem dar a certificação orgânica. Nós aqui não podemos certificar o nosso óleo, por que a terra não é nossa. Nós trabalhamos e os outros ganham em cima de nosso trabalho. A Beraca não pode comprar da gente com certificação orgânica, por que nós pegamos o coco de qualquer área da RESEX. Não temos como provar que o fazendeiro não usa agrotóxico [...] Hoje o governo, o ICMBio, diz que não tem recurso. Eu sou secretaria do CNS e sei que tem recurso. Sei que a demanda é muito grande, não é só a nossa reserva. Mas, sabemos que há meios de resolver as demandas maiores, ir para o Congresso Nacional, por meio de emenda. Pra que haja a regularização da reserva depende muito dessas questões parlamentares. Só que os parlamentares daqui não querem nem saber daqui. [...] Não existia diálogo entre os gestores anteriores (do ICMBio) e os fazendeiros. A gestão atual busca esse diálogo o que inclusive permite que nós possamos utilizar partes da RESEX para coletar o coco [...] Foi feita uma demarcação da RESEX, em 2004, se não me engano. Outra foi feita em 2012. A demarcação e sinalização em placas feitas pelo ICMBio, os fazendeiros já meteram bala em todas essas placas. Uma reserva que já tem mais de 20 anos e o governo não se mobiliza para indenizar os fazendeiros. Aí não tem como não rolar conflito (Farinha, descrição sobre território, gravada em 17 de Maio de 2016).

A transcrição de Farinha revela o quão importante é a regularização fundiária na RESEX, para que haja, de acordo com nossa orientação no envolvimento ambiental, uma efetiva justiça social, bem como a garantia da subsistência dos extrativistas. Farinha aponta que há três décadas as terras da atual área da RESEX não possuíam proprietários e que um órgão do governo federal, o GETAT - extinto em 1987 -, concedeu o título para algumas pessoas. Isto, de acordo com a quebradeira de coco, tornou-se um fator de dificuldade para a atual condição de regularização fundiária na RESEX, visto que há a necessidade de indenização para os atuais proprietários.

Aqui, revela-se um papel dúbio do Estado, na medida em que ao mesmo tempo e no mesmo espaço, há a criação da reserva extrativista, na qual o Estado atua a favor das quebradeiras de coco, e por outro, este mesmo Estado, emite títulos de posse das terras, atuando em prol dos fazendeiros.

Ainda referente à regularização, Farinha comenta sobre o descaso de políticos do Tocantins para com a condição fundiária da reserva. Para ela, por serem representantes do povo no governo federal, estes revelam o desinteresse do Estado, representado, inclusive, pela gestão superior do ICMBio, em resolver essa questão. Tal afirmação advém da sua vivência como representante no CNS - Conselho Nacional dos Extrativistas -, pois a extrativista indica que há verbas de emendas 
que poderiam vir a ser destinadas para a regularização fundiária, mesmo que em etapas. Isso já denotaria não apenas o início do processo de regularização, bem como traria uma carga simbólica no concernente à luta da efetiva territorialização por parte dos extrativistas na RESEX.

Assim, o que vemos é o Estado agindo de acordo com a lógica do mundo moderno-colonial, ao sobrepor a lógica privada sobre o uso coletivo da terra, ao dificultar uma efetiva territorialização de povos que historicamente estão envolvidos com o ambiente. Isto, por conseguinte, prejudica a defesa da conservação de um ambiente com o qual esse mesmo povo possui um rico saber constituído. De acordo com o exposto por Farinha, a corroboração do Estado na sobreposição da lógica privada sobre a coletiva, existente entre os fazendeiros e extrativistas, influencia diretamente em conflitos entre os dois grupos, sendo estes conflitos evidenciados pela destruição feita, a tiros, das placas de sinalização da RESEX, por parte dos fazendeiros.

No descrito por Farinha, a não regularização fundiária implica para além das dificuldades de acesso às terras da RESEX, conforme destacado por outros extrativistas, em perda de renda referente ao valor do óleo comercializado. A quebradeira de coco aponta que pelo fato de não poder haver a certificação de produção orgânica por parte da ARENT, a venda direta do óleo para o exterior necessita ser intermediada por uma empresa sediada no município de Belém-PA. A perda de $\mathrm{R}$ \$ 15,00 por cada litro de óleo comercializado certamente impacta na subsistência de muitas famílias das quebradeiras de coco, que vivem diretamente desse subproduto do babaçu.

Por fim, Farinha revela a aproximação do atual gestor da RESEX em Extremo Norte com os extrativistas, para além das obrigações previstas de um gestor de uma reserva extrativista, o que o difere dos gestores anteriores pelo apoio em buscar um diálogo com os fazendeiros, para que o coco possa vir a ser coletado em áreas mais distantes das comunidades. Entendemos esta negociação, em uma circunstância momentânea, como algo necessário, pois amplia as possibilidades de subsistência, bem como mantém viva a cultura das quebradeiras de coco.

Fernando Collor fez uma atrocidade de construir uma RESEX, só sobrevoando aqui. Chegaram e decretaram a reserva, só porque viram um vasto babaçual e nada foi feito pela reserva. Não nos deram condição nenhuma de subsistência. $O$ prefeito da cidade, à época, tentou derrubar o decreto, pois ele e os fazendeiros diziam que aqui não existia reserva. Que a terra já tinha dono. A criação da Associação foi fundamental para fortalecer a luta das quebradeiras de coco [...] Diziam (os órgãos ambientais, como Naturatins, IBAMA, ICMBio) que não podia caçar, não possuíam uma desenvoltura com a comunidade. Era uma preocupação exclusiva com a preservação do babaçual. De que adianta preservar e o povo morrer de fome? [...] O governo do TO nunca foi a favor da reserva extrativista. E agora, nós temos uma tal senadora, que não gosto nem de falar o nome (senadora Kátia Abreu), que chegou aqui e disse que não tem coco babaçu. Que aqui é a maior bacia leiteira do Bico do Papagaio. Será que ela não entende nada de 
vegetação?[...] Com o gestor atual da RESEX, todas as comunidade se dá muito bem com ele. Ele é o verdadeiro "Severino" pra gente. Pau pra toda obra, por que ele se preocupa com a gente. As quebradeiras junta o coco dentro do mato, no babaçual mais distante mesmo, e o gestor vai buscar, com o carro do ICMBio. A gente tem um grande parceiro aqui. Coisa que em outras RESEX não existe. Às vezes há conflito com o pessoal do ICMBio e extrativistas em outros lugares, essas coisas de proteção ambiental que não leva em consideração o povo que ali existe. De que adianta só proteger bicho e verde? (Farinha, descrição sobre babaçual, gravada em 17 de Maio de 2016).

O babaçual é descrito por Farinha para além de uma riqueza do ambiente a ser conservada. Por conseguinte, o envolvimento ambiental é contemplado, também em seus dois outros pilares, na medida em que o ambiente é visto como aquele que propicia a subsistência dos extrativistas na RESEX. Também quando a quebradeira de coco revela um descaso com a população existente na área da reserva, por parte do então presidente da república na época da criação da reserva em Extremo Norte, ao não oferecer subsídios para a manutenção dos povos ali existentes, bem como de não utilizar-se de estudos técnicos para a criação de uma RESEX. Há, inclusive, a falta de interesse dos poderes nas mais diversas escalas, sejam municipais, estadual ou federal, em apoiar a situação dos extrativistas, em especial no concernente à regularização fundiária, denotando que a justiça social é uma luta do povo contra aqueles que o representa.

Farinha aponta a relevância do senso comunitário, no momento em que a mesma condiciona a criação da ARENT para manter viva a luta pelo vivido das quebradeiras de coco. Ressaltamos, de maneira importante, o envolvimento e o suporte dado pelo atual gestor da RESEX, que contribui para que se mantenha pulsando a riqueza da sociobiodiversidade, por meio da organização comunitária, segundo a descrição da quebradeira de coco. Logo, vemos uma solidariedade em uma relação horizontal de respeito entre o gestor e as quebradeiras de coco, em uma parceria que visa à subsistência das famílias e à defesa de um modo de vida copartícipe na conservação do ambiente existente na área da RESEX.

A quebradeira de coco afirma, por duas vezes, no trecho transcrito anteriormente, a excessiva preocupação existente com a preservação da vegetação e de animais existentes em reservas extrativistas, por parte de diversos órgãos federais. Para Farinha, estes negam a importância das populações humanas existentes nestas áreas, ao não incluírem em suas ações de proteção a subsistência destes povos.

Desta maneira, vemos um discurso de conservação referindo-se exclusivamente a elementos ditos naturais, em uma natureza que nega o humano. Compreendemos, tal qual Diegues (2005), que tal negação representa uma perda na sociobiodiversidade dos mais diversos lugares, haja vista a 
importância do humano, a partir de seu envolvimento, saberes e vivência para a configuração dos mais diversos ambientes existentes na Terra.

Faço muita caieira na roça e trago pra comunidade pra vender. Nas fazendas os donos não deixam, tenho de usar as beiras da estrada ou quintal da casa dos vizinhos mesmo, onde der. O pessoal usa o babaçu pra tudo que é coisa você sabe disso, né? A gente usa da palha, na verdade desde o coqueiro até o coco, a gente usa. Pras cercas dos quintais, pra cobrir as casas, pra fazer carvão, é pra quebrar o coco e usar a amêndoa, é pra fazer o carvão, pra tudo a gente usa o babaçu aqui. Não usamos só o coco em si, apesar que dele temos o óleo, o azeite, mas aqui a nossa riqueza é o babaçual todo. O pessoal aqui vende a casca do coco pra algumas empresas fazerem o carvão. Tem também a torta que serve pra alimentar porco, galinha, peixe. [...] Após o processo de decantação, do óleo, temos a borra que serve para as mulheres fazerem sabão. Tem os artesanatos que é feito das cascas do coco. Temos também a produção do mesocarpo, que serve pro mingau. [...] Nós temos uma parte das beneficiárias que trabalha com o óleo, tem gente que trabalha com o mesocarpo, tem gente que trabalha com o azeite. Essa diversificação é boa, por que quando a produção de alguma coisa tá em baixa, sempre tem algo que tá em alta. Nosso projeto após a regularização fundiária é que a gente deixe o entorno e vá pro interior da reserva mesmo. Trabalhar na área da RESEX, não só com o babaçu, mas com outras atividades que venham melhorar a qualidade de vida. Nosso povo tem um conhecimento aqui muito grande. Sabemos como usar muito do babaçu. Infelizmente, hoje é na benevolência dos fazendeiros que conseguimos o nosso sustento (Farinha, descrição sobre saber $e$ cultura, gravada em 04 de Fevereiro de 2015).

O saber e a cultura dos extrativistas, concernentes ao babaçual, expressam toda a riqueza de um povo, constituída em seu lugar. Tendo como aporte o envolvimento ambiental tal riqueza ressoa na luta pela subsistência e por uma justiça social.

A subsistência é vista em todo o trecho anterior descrito por Farinha. A mesma inicia informando que produz carvão para vender à comunidade. A quebradeira de coco continua em sua descrição, destacando o aproveitamento de "tudo" do babaçu, por parte dos comunitários. Este "tudo" vai desde a palha do babaçual, para a construção de cercas e telhados, à produção do óleo e do azeite - produtos que mais propiciam renda aos extrativistas -, à fabricação do carvão por meio das caieiras, até à borra existente após a produção do óleo, que serve para fazer sabão.

No revelado por Farinha, a quantidade de subprodutos originados do babaçu é considerada fundamental, pois permite uma diversidade de fontes de rendas. Todos estes subprodutos só existem por conta de um rico saber alicerçado pelos extrativistas com o babaçual, no qual a cultura dessa população auxilia na conservação do ambiente, para além da subsistência já descrita.

Compreendemos como justiça social o exposto por Farinha, no referente à luta pelo direito de conceder aos extrativistas a possibilidade de construírem uma territorialização que permita o uso 
legítimo do território, sem que haja a concessão por parte dos fazendeiros. Isto se refere não apenas aos subprodutos originados do babaçu, mas também à produção de alimentos na roça, bem como da própria produção de carvão.

Assim, as quebradeiras de coco buscam o acesso a um território que é seu de direito, a partir do momento da criação, via decreto, da reserva extrativista, e que mais do que isso: é seu território. Essa busca ocorre por intermédio de uma cultura e de uma territorialidade reveladas no contexto da existência que resiste e de um vivido de pertencimento e intimidade com o lugar.

\section{Considerações Finais}

Intentamos contrapor a ideia de que o desenvolvimento sustentável é único para todos os lugares. Por conseguinte, apresentamos uma alternativa à sustentabilidade, que se realiza no lugar e que tem como arcabouço o paradigma pós-colonial e a fenomenologia, em um movimento de emergência que visou compreender um caminho legitimamente sustentável.

A busca por tal compreensão emergiu, do mesmo modo, epistemicamente, como uma vertente polifônica ao que diz ser o desenvolvimento e o progresso, alicerçados na ideia de desenvolvimento sustentável, como se este fosse homogêneo nos diversos espaços tempos. A vivência, a resistência e a autonomia das quebradeiras de coco na reserva extrativista do Extremo Norte do Tocantins é um dos exemplos possíveis do que constitui o que nominamos de caminho sustentável. Caminho estruturado ontologicamente pelo envolvimento ambiental - um viés relacional entre o ser humano e seus pares para com a natureza, a partir de concepções que valorizam as experiências vividas entre pessoas e lugares, nas quais prevaleçam a subsistência, a conservação ambiental e a justiça social.

Na Reserva Extremo Norte do Tocantins, vivenciamos um espaço de inspiração que possibilita a valorização de saberes historicamente subjugados pelo mundo moderno-colonial. Saberes pautados em um fortalecimento da relação do ser humano com a natureza. Relação baseada em uma autonomia que se realiza como uma empreitada coletiva, na qual a dimensão social envolvendo a justiça, a subsistência e a conservação do ambiente - é o alicerce e o norteador do vivido dos extrativistas.

Logo, um caminho sustentável na RESEX - possível no mundo real e potencializado por intermédio das ricas descrições apresentadas - possibilita compreendermos que com a própria 
comunidade de extrativistas há um aspecto prático, de se propor uma alternativa à sustentabilidade, pelo que só existe em seu próprio cotidiano.

Para além dos limites da reserva, compreendemos também a existência de um enorme potencial, em diversos outros lugares, para se pensar como a sustentabilidade não é um conceito absoluto, haja vista que a sociedade não é única. Portanto, há uma diversidade de possibilidades de sermos sustentáveis em uma realidade complexa que extrapola os ideais de um modelo de desenvolvimento sustentável.

Por conseguinte, compreendemos, também, a sustentabilidade reconfigurando-se e sendo produzida em um diálogo com outros saberes, rompendo com o pensamento produzido pela sociedade moderno-colonial que impõe uma única maneira de ser sustentável, desprezando as experiências vividas e o os diversos saberes.

Por fim, acreditamos que uma relação, a partir do envolvimento ambiental, na qual as quebradeiras de coco da Reserva Extrativista do Extremo Norte do Tocantins possuem com o seu território propiciam a conservação da sociobiodiversidade, em termos práticos. Trata-se de um movimento autônomo que visa à subsistência de sua comunidade a partir de ricos saberes constituídos no lugar, possibilitando uma dinâmica territorial própria, erigida pelo protagonismo dos povos que constituem o seu território.

\section{Referências}

COMISSÃO MUNDIAL SOBRE MEIO AMBIENTE E DESENVOLVIMENTO. Nosso futuro Comum. Rio de Janeiro: Fundação Getúlio Vargas, 1991.

DIEGUES, A.C.S. Sociobiodiversidade. In: FERRARO Jr, Luiz Antônio (Org.). Encontros e Caminhos: Formação de Educadoras (es) Ambientais e Coletivos Educadores. Brasília: Ministério do Meio Ambiente, Diretoria de Educação Ambiental, p.305-311, 2005.

GALEFFI, D.A. O que é isto: A fenomenologia de Husserl? Ideação. Feira de Santana, n. 5, p.1336, 2000.

GARNICA, A. V. M. Algumas notas sobre pesquisa qualitativa e fenomenologia. Interface Comunicação, Saúde, Educação. São Paulo, v. 1, n. 1, p. 109-119, 1997.

HAESBAERT, R. Da desterritorialização à multiterritorialidade. In: ENCONTRO DE GEÓGRAFOS DA AMÉRICA LATINA, 10., 2005, São Paulo. Anais... São Paulo: Universidade de São Paulo. 2005. p.6774-6792.

LEFF, E. Epistemologia Ambiental. 4. ed. São Paulo: Cortez, 2006. 
Discursos Sustentáveis. Tradução de Silvana Cobucci Leite. São Paulo: Cortez, 2010.

MERLEAU-PONTY, M.. Fenomenologia da percepção. Tradução de Carlos Alberto Ribeiro de Moura. 2.ed. São Paulo: Martins Fontes, 1999.

Conversas 1948. Tradução de Fábio Landa e Eva Landa. São Paulo: Martins Fontes, 2004.

MICHAELIS. Moderno Dicionário da Língua Portuguesa. Disponível em: <http://michaelis.uol.com.br/moderno/portugues/index.php>. Acesso em: 10 jul. 2015

MIGNOLOGO, W. A colonialidade de cabo a rabo: o hemisfério ocidental no horizonte conceitual da modernidade. In: LANDER, Edgardo (Org.). A colonialidade do saber: eurocentrismo e ciências sociais - Perspectivas latino-americanas. Buenos Aires: Clacso, 2005.

Desobediência Epistêmica: A opção descolonial e o significado de identidade em política. Cadernos de Letras da UFF. Rio de Janeiro, n.34, p.287-324, 2008.

RELPH, E. Reflexões sobre a Emergência, Aspectos e Essência de Lugar. In: MARANDOLA Jr, Eduardo; HOLZER, Wherther; OLIVEIRA, Lívia de (Orgs). Qual o espaço do lugar?: geografia, epistemologia, fenomenologia. São Paulo: Perspectiva, p.17-32, 2012.

RODRIGUES, A. M. Desenvolvimento Sustentável dos conflitos de classes para o conflito de gerações. In: SILVA, Jose Borchacchielo da; LIMA, Luiz Cruz; DANTAS, Eustogio Wanderlei (Orgs.). Panorama da Geografia Brasileira. São Paulo: Annablume, p.77-100, 2006.

SANTOS, B. S. A Gramática do Tempo: para uma nova cultura política. 3. ed. São Paulo: Cortez, 2010.

SILVA, L. A. G. C. Biomas presentes no Estado do Tocantins. Brasília: Consultoria Legislativa, ago. $2007 . \quad$ Disponível em: < http://www.terrabrasilis.org.br/ecotecadigital/images/abook/pdf/1sem2015/Passivo/biomastocantins . .pdf $>$

SOUZA, L. B. Percepção Ambiental e a Fenomenologia de Husserl. In: SILVA, Valéria Cristina, CORCÍNIO JUNIOR, Givaldo Ferreira (Orgs.). Natureza e representações imaginárias. Curitiba, Appris, 2013.

TUAN, Y. Topofilia: Um estudo da percepção, atitude e valores do meio ambiente. Tradução de Lívia de Oliveira. Londrina: Eduel, 2012.

UFV/ICMBio. Apoio ao processo de identificação das famílias beneficiárias e diagnóstico socioprodutivo em Unidades de Conservação Federais. Viçosa-Brasília, 2014.

VIEIRA, F. P. Por um envolvimento na Educação Ambiental. ETD - Educação Temática Digital. Campinas, v. 16, n. 3, p.395-407, 2014.

Artigo recebido em 19/03/2017. Aceito para publicação em 22/05/2017. 